\title{
Modification of NR/BR blend with unsaturated thermo plastic polyurethane; polyurethane synthesis, blend morphology, vulcanization, and vulcanizate properties
}

\author{
Urška Šebenik, Ida Poljanšek, Matjaž Krajnc*
}

University of Ljubljana, Faculty of Chemistry and Chemical Technology, Aškerčeva 5, P. O. Box 537, SI-1001 Ljubljana, Slovenia; Fax +386 12419 541; matjaz.krajnc@fkkt.uni-lj.si

(Received: 13 October, 2005; published: 21 July, 2006)

\begin{abstract}
The unsaturated polyurethane (PU) was synthesized, characterized, and used in rubber compound. To study the effect of PU incorporation in the blend a systematic approach was used where PU was added to the natural rubber (NR), butadiene rubber (BR), and NR/BR blends. Different un-vulcanized and vulcanized compounds were characterized and the vulcanization process was investigated. It was observed that the synthesized PU was able to crosslink with the rubber compounds during the vulcanization process. The lowered temperature of melting indicated a better processability of the composites containing thermoplastic PU which melted at processing temperature, thereby allowing improvement in blend viscosity mold flow and to some extent in its homogeneity, although the mechanical properties such as hardness, tensile strength, modulus, and elongation at break did not differ significantly from the properties of elastomer blends without PU. The thermal stability of compounds with PU did not significantly worsen.
\end{abstract}

\section{Introduction}

Blending of elastomers is carried out for three main reasons: improvement of the technical properties of the original elastomer, achievement of better processing behaviour, and lowering of compound cost. All elastomers have deficiencies in one or more properties and blending is a way of obtaining optimum all-around performance. Compounds with good properties also need to be capable of factory processing without difficulty and of providing uniformity in behaviour [1-2].

Blends occur at different hierarchical scales in the material range employed in the industry. Composite products such as tires, hoses, belts, and air springs are composed of metal wire, textile cord, and elastomeric compounds, which form a rubber matrix. The rubber matrix itself is a compound of elastomer, filler, and plasticizer. The elastomer phase can also be a blend of different elastomers [1]. However, there are technological problems arising from some types of mutual immiscibility which can exist between dissimilar elastomers. Three main types of immiscibility have generally been noted; the thermodynamic immiscibility, immiscibility due to viscosity mismatch, and immiscibility due to the cure rate mismatch [3]. The commercially useful polymer-polymer combination is linked by intermolecular forces such as van der Waals forces or dipole moments and exhibits 
sufficient thermodynamic compatibility to prevent the polymer phases from separating during melt processing.

Polybutadiene rubber (BR), natural rubber (NR), and their blends are important materials in rubber industry; therefore the morphology of NR/BR blends, which affects blend properties, has been studied by several authors, using different techniques, and methods. NR/BR blends were reported to be mutually compatible by observing a single glass transition temperature in dilatometric measurements [4], whereas the microscopic investigations of the NR/BR blend showed it to be heterogeneous [5]. Hess et al. demonstrated the phase structure of NR/BR blends to consist of discrete zones of the minor polymer dispersed in a continuous matrix of the major polymer [6]. Hourston et al. quantitatively characterized the interfaces in NR/BR elastomer blends by the use of temperature modulated differential scanning calorimetry [7]. A quantitative analysis using the differential of the heat capacity versus the temperature signal allowed them to calculate the weight fractions of pure NR, pure BR, and NR/BR interface in a NR/BR blend. They observed two distinct glass transition temperatures in blends thermograms and reported that NR is partially miscible with BR, with the maximum amount of interface at the 50:50 blend compositions. Bualek et al. studied the effect of diblock copolymers of isoprene and butadiene as a compatibilizer for NR/BR blends [8]. The morphology studies of rubber blends with compatibilizer by differential scanning calorimetry and dynamic mechanical analysis indicated an improvement of blends homogeneity though the two phase-structures still existed. Bauer and Duddley measured the dynamic mechanical properties of different rubber blends including a NR/BR blend at different stages of cure [9]. They concluded that the phase heterogeneity in rubber blends almost always prevails. They stated that the compatibilization of these blends can be achieved through a co-vulcanization process which promotes crosslinks between the heterogeneous polymer phases. The compatibility achievement was confirmed by observing that the original two loss peaks present in the uncured blend joined into one intermediate loss peak on vulcanization. Only one single intermediate loss peak for a vulcanized blend was observed also by Corish [10]. Recently, dielectric measurements were used to investigate the compatibility of different types of rubber blends [11]. The authors concluded, from the dielectric measurements, the calculation of heat of mixing, and the scanning electron microscopy, that the vulcanized NR/BR blends are compatible through the whole investigated range of concentrations. By interpreting the SEM image, in the same work, the authors stated that the BR/NR blend was compatible as dark and bright regions representing both polymers were distributed homogeneously and none of the regions had phase separation. Hasegawa et al. [12] employed small-angle neutron scattering and timeresolved small-angle light scattering techniques to study the static and dynamic phase behavior of protonated polyisoprene and deuterated polybutadiene binary blends with particulate microstructures. They observed lower critical solution temperature (LCST) type phase behaviour for the blends under investigation.

Since the elastomer blends are normally two or more phase systems the distribution of additives between phases is also not necessarily uniform [10,13]. Moreover, even if the distribution of the curatives was uniform, the different elastomers in the blend would seldom cure at identical rates. To estimate the reactivity of vulcanization oscillating disk rheometry (cure meter) and/or differential scanning calorimetry (DSC) are usually used. Rheometers give information on the scorch delay and optimum cure time from the torque-time curve reflecting the degree of vulcanization. DSC measures the enthalpy and peak temperature of vulcanization to estimate the 
reactivity between rubber and sulphur. The kinetic parameters calculated from DSC and rheometer measurements are often incompatible because the complex vulcanization reaction system is multi-exothermal and it is difficult to isolate the heat due to crosslinking in the DSC thermograms [14]. However, by using both techniques more useful information can be obtained. Chough and Chang [15] used both techniques to study the relationship between vulcanization reactivity and chemical structure for natural rubber, butadiene rubber, styrene-butadiene rubber, and their blends. Huson et al. [16] used dynamic mechanical analysis to obtain an indication of the extent of vulcanization in each of the phases in a BR/NR blend.

The objective of this work was to study the possibility of adding thermoplastic polyurethane (PU) to the NR/BR blend to improve its processability and to obtain a more homogeneous NR/BR blend. An unsaturated PU was used to enable its crosslinking with rubber compounds during the vulcanization process. Therefore, a comprehensive study was done where the PU synthesis, PU characterization, preparation and characterization of different un-vulcanized blends, vulcanization process and vulcanized product properties were considered. To study the effect of $\mathrm{PU}$ incorporation in the blend a systematic approach was used where $\mathrm{PU}$ was added to NR, BR, and NR/BR blends.

\section{Results and discussion}

\section{PU synthesis}

The synthesis of unsaturated PU was carried out in two separate steps. In the first step an $\mathrm{N}=\mathrm{C}=\mathrm{O}$ terminated prepolymer was formed due to the reaction between diisocyanate $\mathrm{N}=\mathrm{C}=\mathrm{O}$ groups and polyol $\mathrm{O}-\mathrm{H}$ groups, while in the second step the reaction between prepolymer free $\mathrm{N}=\mathrm{C}=\mathrm{O}$ groups and $\mathrm{HEMA} \mathrm{O}-\mathrm{H}$ groups occurred. Therefore, the FTIR-ATR in-line spectroscopy was utilized to monitor the reaction of polyol with diisocyanate in the first step and HEMA with prepolymer in the second step. The spectra of unreacted TDI, polyol, and HEMA are presented in Figure 1, while the assignments of characteristic peaks are listed in Table 1.

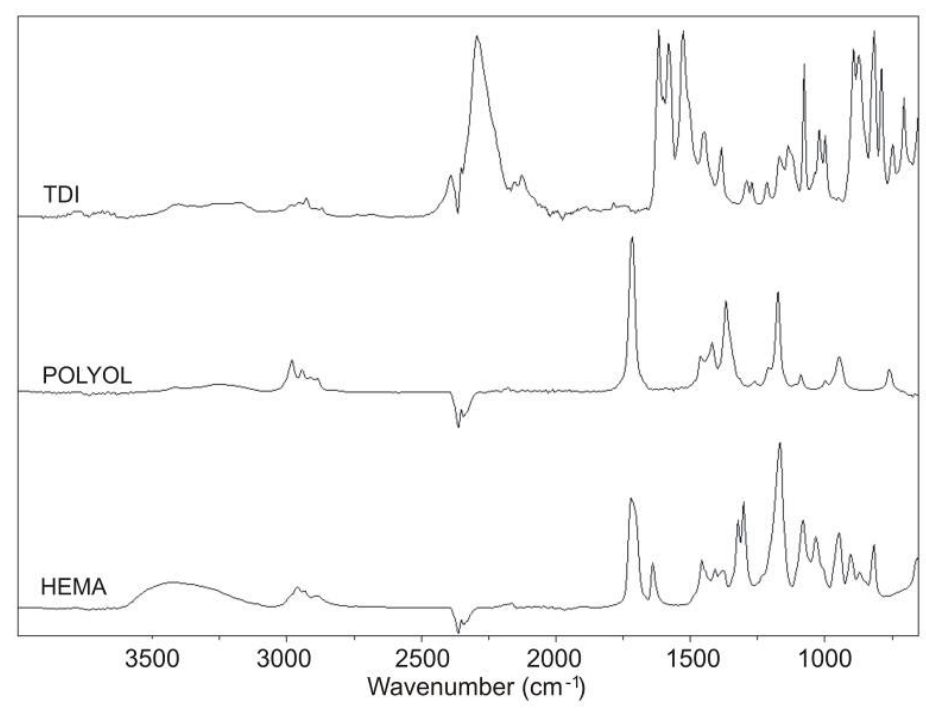

Fig. 1. The IR spectra of TDI, polyol and HEMA. 
During both steps of the synthesis the spectra were collected every 30 seconds. The resulting three dimensional spectra are shown in Figure 2. In Table 1 the investigated peaks belonging to the most characteristic functional groups in the PU synthesis are listed and assigned. The absorbance profiles for assigned peaks were drawn in autoscale mode (Figure 3).

Tab. 1. FTIR-ATR characteristic peaks assignment for polyurethane synthesis.

\begin{tabular}{lc}
\hline Functional group & Wavenumber $\left(\mathrm{cm}^{-1}\right)$ \\
\hline Polyol and HEMA O-H stretching & 3547 \\
Secondary urethane $\mathrm{N}-\mathrm{H}$ stretching & 3350 \\
Isocyanate asymmetric $\mathrm{N}=\mathrm{C}=\mathrm{O}$ stretching & 2277 \\
Polyol, HEMA, and urethane C=O & $1733-1725$ \\
stretching & \\
HEMA C=C stretching & 1637 \\
Secondary urethane N-H bending & 1532 \\
Urethane C-O stretching & 1220
\end{tabular}

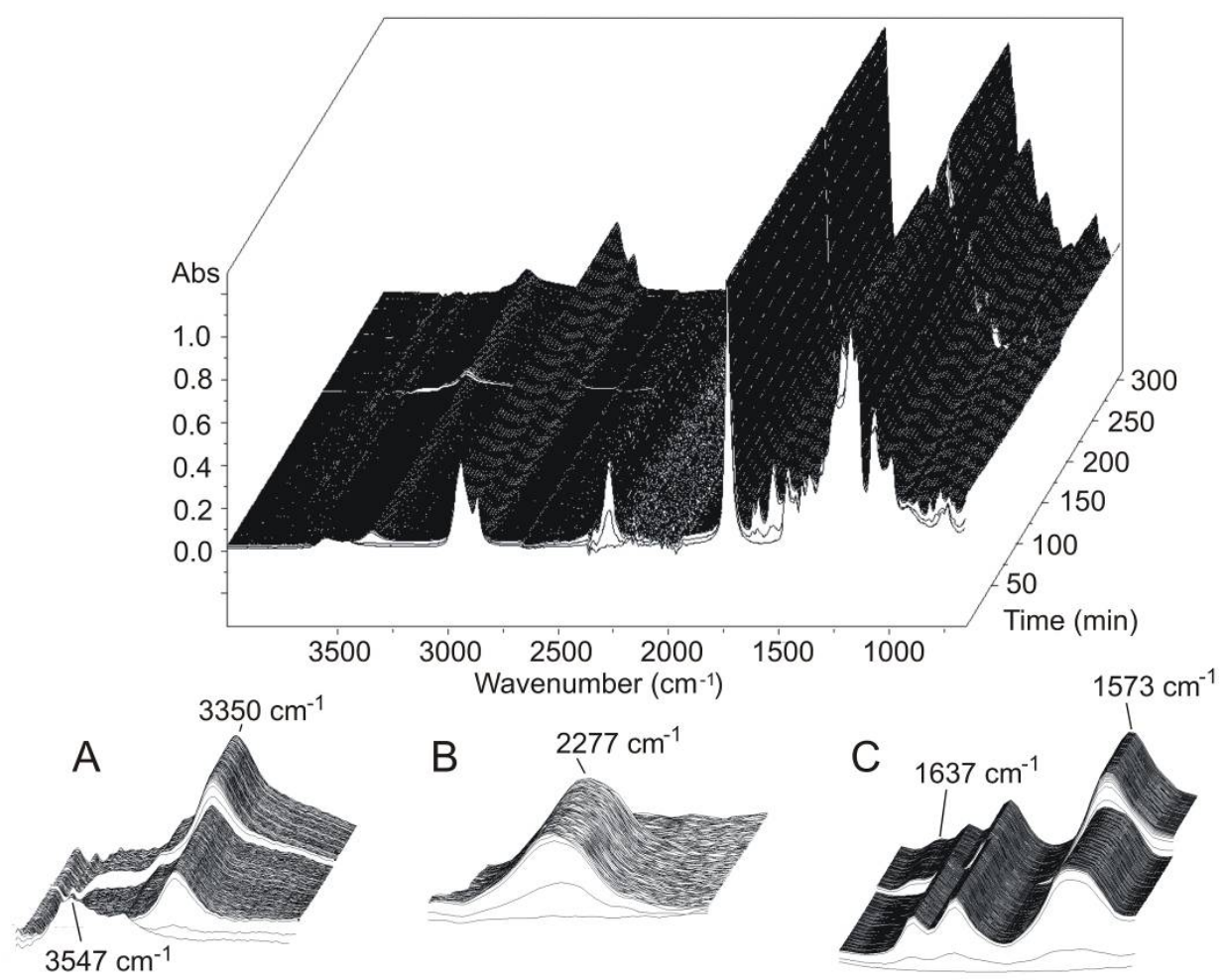

Fig. 2. The IR spectra in the wave number range of interest for the PU synthesis; (A) $\mathrm{O}-\mathrm{H}$ groups at $3547 \mathrm{~cm}^{-1}$ and N-H urethane bond at $3350 \mathrm{~cm}^{-1}$, (B) N=C=O groups at $2277 \mathrm{~cm}^{-1}$, and $(\mathrm{C}) \mathrm{C}=\mathrm{C}$ bonds at $1637 \mathrm{~cm}^{-1}$ and $\mathrm{N}-\mathrm{H}$ urethane bond at $1532 \mathrm{~cm}^{-1}$. 


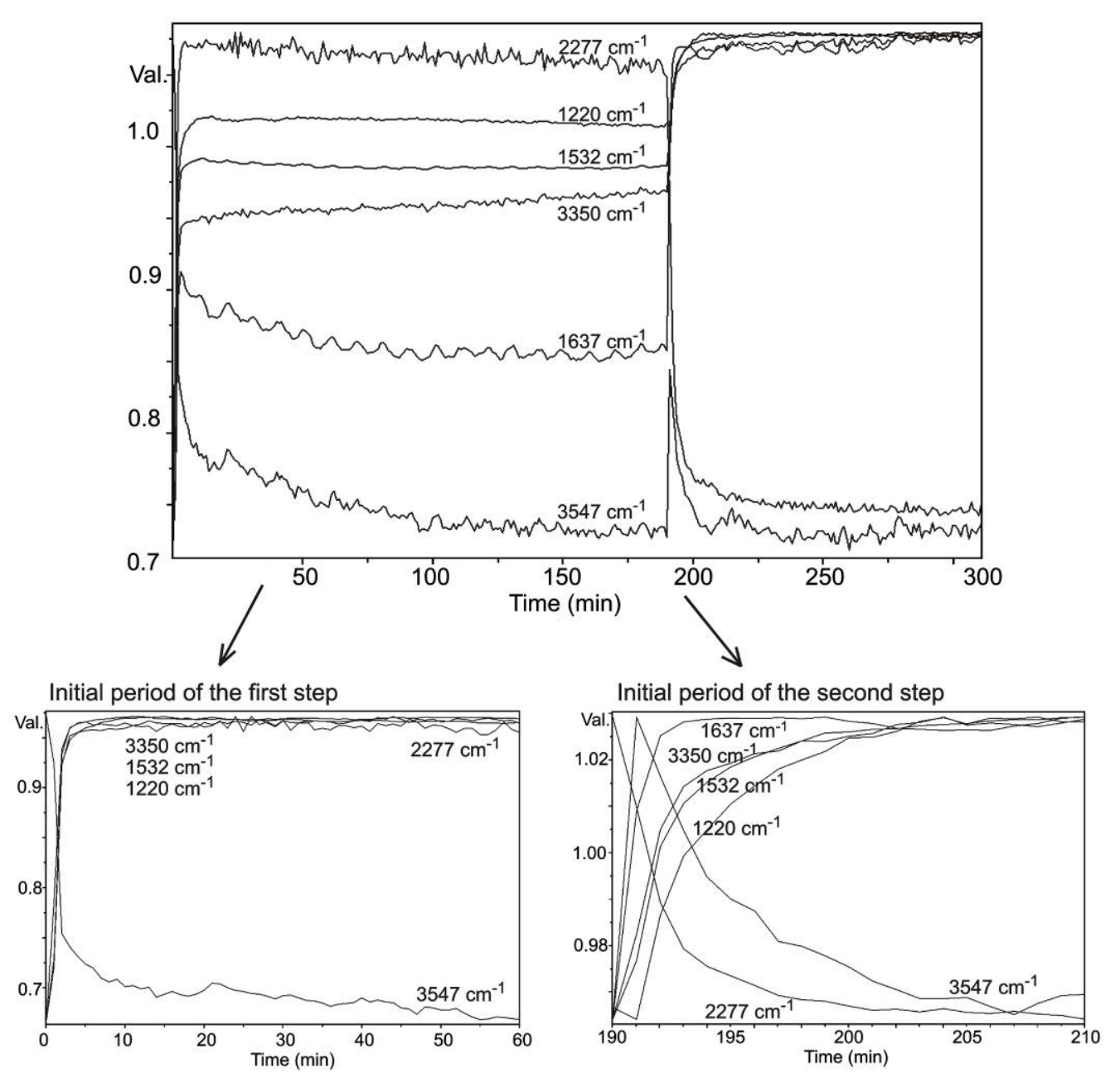

Fig. 3. The relative absorbance profiles for $\mathrm{O}-\mathrm{H}$ groups at $3547 \mathrm{~cm}^{-1}, \mathrm{~N}-\mathrm{H}$ urethane bond at 3350 and $1532 \mathrm{~cm}^{-1}, \mathrm{~N}=\mathrm{C}=\mathrm{O}$ groups at $2277 \mathrm{~cm}^{-1}, \mathrm{C}=\mathrm{C}$ bonds at $1637 \mathrm{~cm}^{-1}$, and $\mathrm{C}-\mathrm{O}$ urethane bond at $1220 \mathrm{~cm}^{-1}$

It can be observed in the Figures 2 and 3 that the reaction between polyol $\mathrm{O}-\mathrm{H}$ groups $\left(3547 \mathrm{~cm}^{-1}\right)$ and diisocyanate $\mathrm{N}=\mathrm{C}=\mathrm{O}$ groups $\left(2277 \mathrm{~cm}^{-1}\right)$ started immediately after the first diisocyanate addition. By this reaction urethane groups were formed and signals of the $\mathrm{N}-\mathrm{H}$ urethane bond at 3350 and $1532 \mathrm{~cm}^{-1}$, and a signal of the $\mathrm{C}-\mathrm{O}$ urethane bond at $1220 \mathrm{~cm}^{-1}$ emerged and increased. At the same time the $\mathrm{O}-\mathrm{H}$ signal at $3547 \mathrm{~cm}^{-1}$ decreased as a result of the reaction, while the $\mathrm{N}=\mathrm{C}=\mathrm{O}$ signal at 2277 $\mathrm{cm}^{-1}$ increased due to the diisocyanate addition. After the addition of the diisocyanate was completed only a minor decrease of the $\mathrm{N}=\mathrm{C}=\mathrm{O}$ signal was observed as a result of its reaction with unreacted polyol $\mathrm{O}-\mathrm{H}$ groups. The change of the $\mathrm{N}=\mathrm{C}=\mathrm{O}$ absorbance peak magnitude was minimal because at this stage of the synthesis the amount of unreacted polyol $\mathrm{O}-\mathrm{H}$ groups were already small, whereas the concentration of the isocyanate groups were still high. After 190 minutes of reacting polyol with diisocynate HEMA was added which resulted in $\mathrm{O}-\mathrm{H}$ signal increase and the occurrence of a $\mathrm{C}=\mathrm{C}$ signal at $1637 \mathrm{~cm}^{-1}$ (Figures 2 and 3 ). From this point forward HEMA $\mathrm{O}-\mathrm{H}$ groups reacted with free $\mathrm{N}=\mathrm{C}=\mathrm{O}$ groups of the prepolymer. Again urethane groups were formed and an increase of absorbance at corresponding wavenumbers was observed. After the second step was completed the absorbance's at $3547 \mathrm{~cm}^{-1}$ (peak belonging to the $\mathrm{O}-\mathrm{H}$ groups) and $2277 \mathrm{~cm}^{-1}$ (peak belonging to 
the $\mathrm{N}=\mathrm{C}=\mathrm{O}$ group) fell to constant values indicating the end of the chemical reaction. As in the last spectrum in Figure 2 (at $310^{\text {th }}$ minute) no peaks of the $\mathrm{O}-\mathrm{H}$ and $\mathrm{N}=\mathrm{C}=\mathrm{O}$ groups could be observed and it might be concluded that these groups were consumed and that the inclusion of $\mathrm{C}=\mathrm{C}$ bond in the $\mathrm{PU}$ chain occurred.

\section{PU characterization}

To confirm the desired PU chemical structure NMR analysis of starting reagents, prepolymer, and PU were performed. Figure 4 represents the ${ }^{13} \mathrm{C}$ spectrum of the synthesized PU.

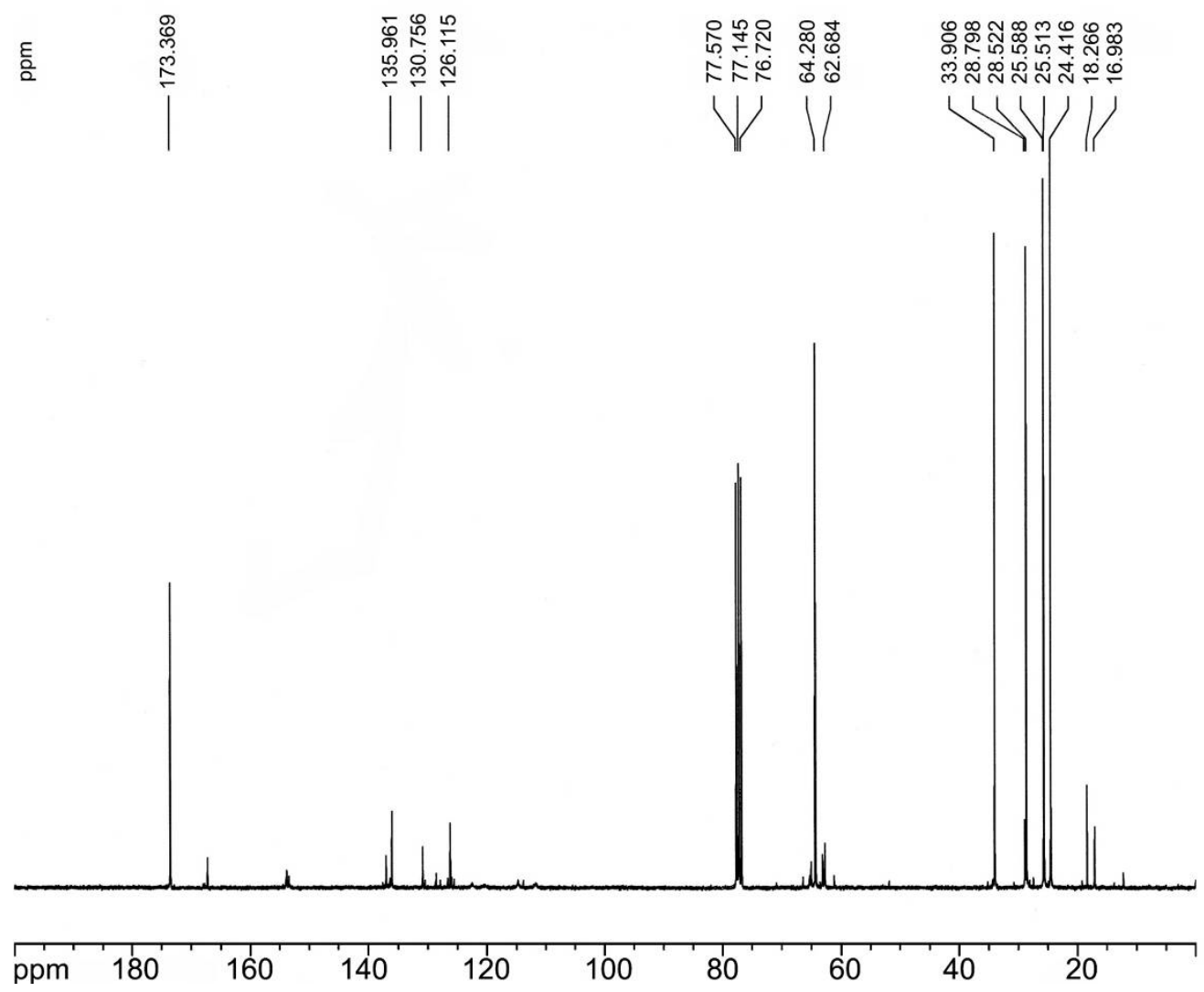

Fig. 4. The ${ }^{13} \mathrm{C}$ NMR spectrum of the synthesized $\mathrm{PU}$ in $\mathrm{CDCl}_{3}$.

In Table 2 the most characteristic chemical shifts, which belonged to different carbon atoms built in the PU structure, are listed. The PU spectrum had characteristic ${ }^{13} \mathrm{C}$ signals of the polyol plus additional signals of HEMA, TDI, and the urethane group. No signal corresponding to the carbon atom of the $\mathrm{N}=\mathrm{C}=\mathrm{O}$ group was observed in the PU spectrum which was in accordance with the results obtained by FTIR-ATR inline spectroscopy which indicated a very high conversion of isocyanate groups after the PU synthesis. In spectra of TDI and $\mathrm{N}=\mathrm{C}=\mathrm{O}$ terminated prepolymer the signal of the $\mathrm{C}$ atom from the $\mathrm{N}=\mathrm{C}=\mathrm{O}$ group occurred at chemical shift $132.8 \mathrm{ppm}$.

A DSC thermogram of PU is presented in Figure 5 . The curve showed a broad glass transition with the glass transition temperature at $-24.9^{\circ} \mathrm{C}$ and with corresponding change of heat capacity of $1.60 \mathrm{Jg}^{-1} \mathrm{~K}^{-1}$. The slightly bimodal curve shape in the broad glass transition region indicated that it is possible that the PU had two glass transitions - one belonging to the PU soft segments and the other to the PU hard 
segments. Regarding the high polyol molecular weight it would be more likely that the PU had two separate glass transitions.

Tab. 2. ${ }^{13} \mathrm{C}$ NMR assignments for polyurethane.

\begin{tabular}{lc}
\hline Structures & Chemical shifts $(\mathrm{ppm})$ \\
\hline $\mathrm{C}=\mathrm{O}$ from polyol & 173.4 \\
$\mathrm{C}=\mathrm{O}$ from HEMA & 168.0 \\
$-\mathrm{O}(\mathrm{CO}) \mathrm{NH}$ - from urethane bond & 153.7 \\
$\mathrm{H}_{2} \mathrm{C}=\mathrm{C}\left(\mathrm{CH}_{3}\right)$ - from HEMA & 136.0 \\
Aromatic $\mathrm{C}$ of TDI & $127.0-130.8$ \\
$\mathrm{H}_{2} \mathrm{C}=\mathrm{C}\left(\mathrm{CH}_{3}\right)$ - from HEMA & 126.1 \\
$-\mathrm{CH}_{2} \mathrm{O}(\mathrm{CO}) \mathrm{NH}$ - from polyol & 64.3 \\
$-\mathrm{CH}_{2} \mathrm{O}(\mathrm{CO}) \mathrm{NH}$ - from HEMA & 62.7 \\
$-\mathrm{CH}_{2} \mathrm{O}-$ from polyol & 51.8 \\
$-\mathrm{O}(\mathrm{CO}) \mathrm{CH}$ - from polyol & 33.9 \\
$-\mathrm{CH}_{2}-$ from polyol & $28.5,25.5$, and 24.4 \\
\hline
\end{tabular}

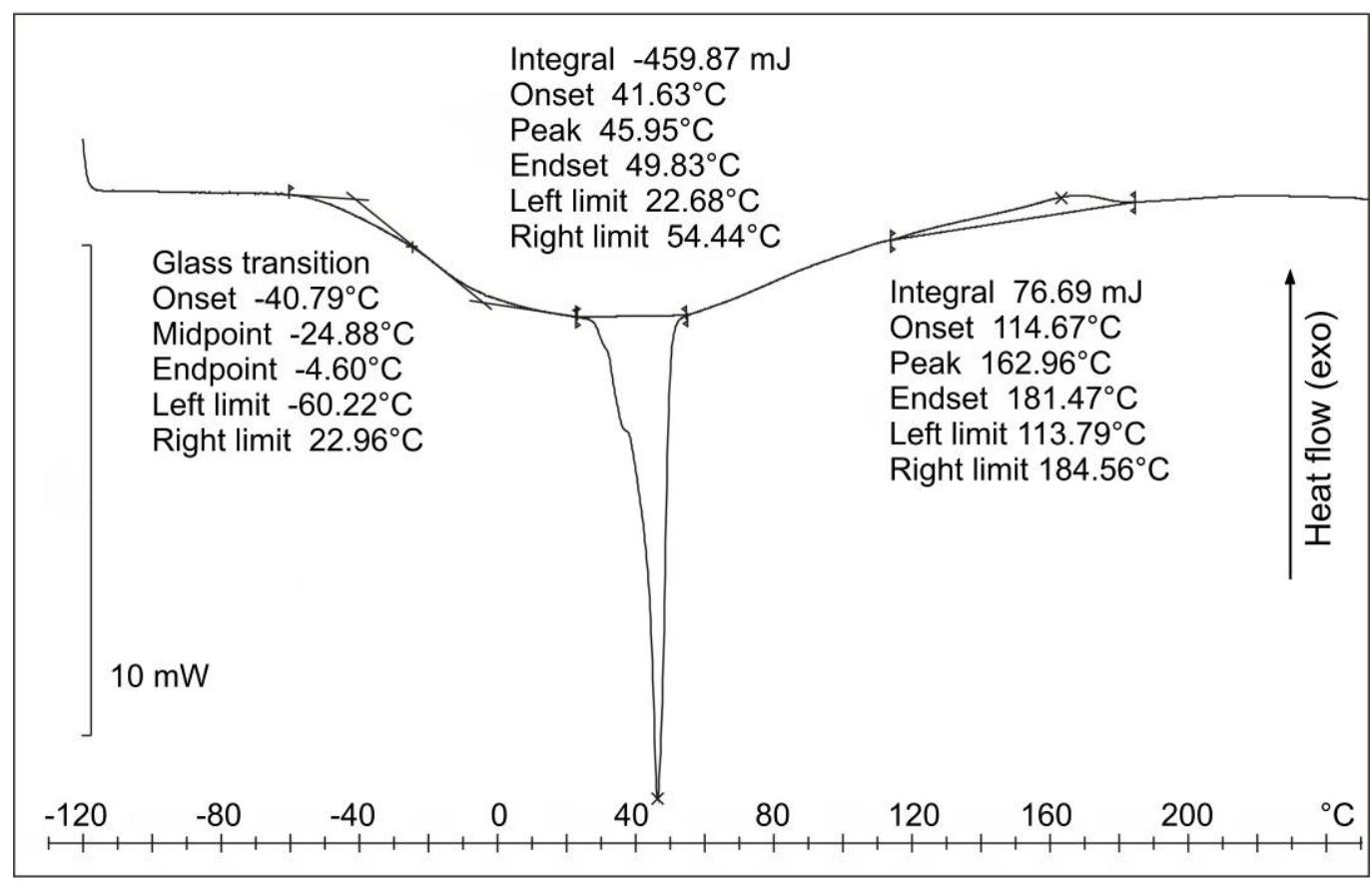

Fig. 5. The DSC thermogram of PU.

If PU has long polyol segments, the phase separation between soft and hard segments is very probable since polyol segments are able to arrange themselves in so called soft domains. It depends on the polyol structure if the soft domains are more amorphous or crystalline. In the case of their high crystallinity degree the glass 
transition of the soft segments is weak, sometimes barely observable or not even observable at all by a common DSC technique. In Figure 5 the confirmation of the presence of crystalline domains can be observed - an endothermic peak due to the soft segments melting at $46{ }^{\circ} \mathrm{C}$. Actually, it was determined that the polyol used had a broad glass transition at cca. $-62{ }^{\circ} \mathrm{C}$ with a low $\Delta \mathrm{C}_{\mathrm{p}}\left(0.26 \mathrm{Jg}^{-1} \mathrm{~K}^{-1}\right)$ and a strong melting peak at cca. $75{ }^{\circ} \mathrm{C}$. Therefore, crystallinity degrees of $\mathrm{PU}$ and polyol were determined by X-ray diffractometry: the crystallinity degree of PU was estimated to be about $19 \%$, while the estimated polyol crystallinity degree was about $27 \%$.

In the DSC thermogram of PU (Figure 5) an exothermic peak at higher temperatures with a maximum at about $170{ }^{\circ} \mathrm{C}$ can be observed. This peak was a result of unsaturated PU self-curing reaction.

For the determination of molecular weights, GPC and ${ }^{1} \mathrm{H}$ NMR were used as two independent methods. The weight average molecular weight and the number average molecular weight of synthesized PU determined by GPC method were $1.2 \cdot 10^{4}$ and $2.2 \cdot 10^{3}$, respectively, the polydispersity index was 5.45 . The molecular weight of PU obtained by the ${ }^{1} \mathrm{H}$ NMR was calculated from the ratio of the signal integrals corresponding to the $-\mathrm{CH}_{3}$ protons of TDI $(2.13-2.30 \mathrm{ppm}),-\mathrm{CH}_{3}$ protons of HEMA $(6.05-6.30 \mathrm{ppm})$, and signals of the polyol chain, with the assumption that each PU macromolecule contained one molecule of polyol, two molecules of TDI, and two molecules of HEMA. The measurements of $-\mathrm{CH}_{3}$ group intensity of TDI and HEMA versus the $-\mathrm{CH}_{2-}$ monomeric unit of polyol, provided the value of number average molecular weight of $2 \cdot 10^{3}$.

\section{Morphology of non-vulcanized NR, BR, and PU compounds}

The microphase structure of non-vulcanized compounds was investigated by the DSC method described above. Conclusions concerning the miscibility and morphology were made on the basis of glass transition temperature $\left(T_{g}\right)$ shifts. The use of $T_{g}$ in determination of polymer/polymer miscibility is based on the premise that a single $T_{g}$ indicates that the domain size is below 2 - $15 \mathrm{~nm}$ [2]. Rubber-rubber blends exhibit more than one glass transition due to their morphology which can be considered to be a multi-phase structure consisting of regions of pure polymers plus the interface multi-component blends. Therefore, $T_{g}$ shifts indicate formation of an interface between different polymer phases. The amount of the interface, which affects $T_{g}$ shifts, depends on mixing efficiency and polymer-polymer miscibility. However, all the glass transition temperatures for such a complex system can be observed only if an appropriate analytical technique is used and if the difference in glass transition temperatures of blend components is not too small. Moreover, it can also occur that a glass transition of one component overlaps with an exothermic or endothermic transition, often due to cold crystallization or melting, of the second component.

The compounding formulations of investigated elastomer blends, PU blend, and PU/elastomer blends are shown in Table 9. Figure 6 illustrates the DSC thermograms of masticated BR, NR, PU, BR/NR, BR/PU, NR/PU, and BR/NR/PU compounds. The obtained data from the thermograms in Figure 6 are presented in Table 3 where glass transition temperatures $\left(T_{g}\right)$, corresponding changes of heat capacity $\left(\Delta C_{p}\right)$, crystallization temperatures $\left(T_{c}\right)$, melting temperatures $\left(T_{m}\right)$, crystallization enthalpy $\left(\Delta H_{c}\right)$, and melting enthalpy $\left(\Delta H_{m}\right)$ are collected. $\Delta H_{c}$ and $\Delta H_{m}$ represent measured values, while $\Delta H_{c B R}$ and $\Delta H_{m B R}$ are calculated values of crystallization and melting enthalpy for the BR weight fraction in the blends, expressed in $\mathrm{Jg}^{-1}$ of BR. 


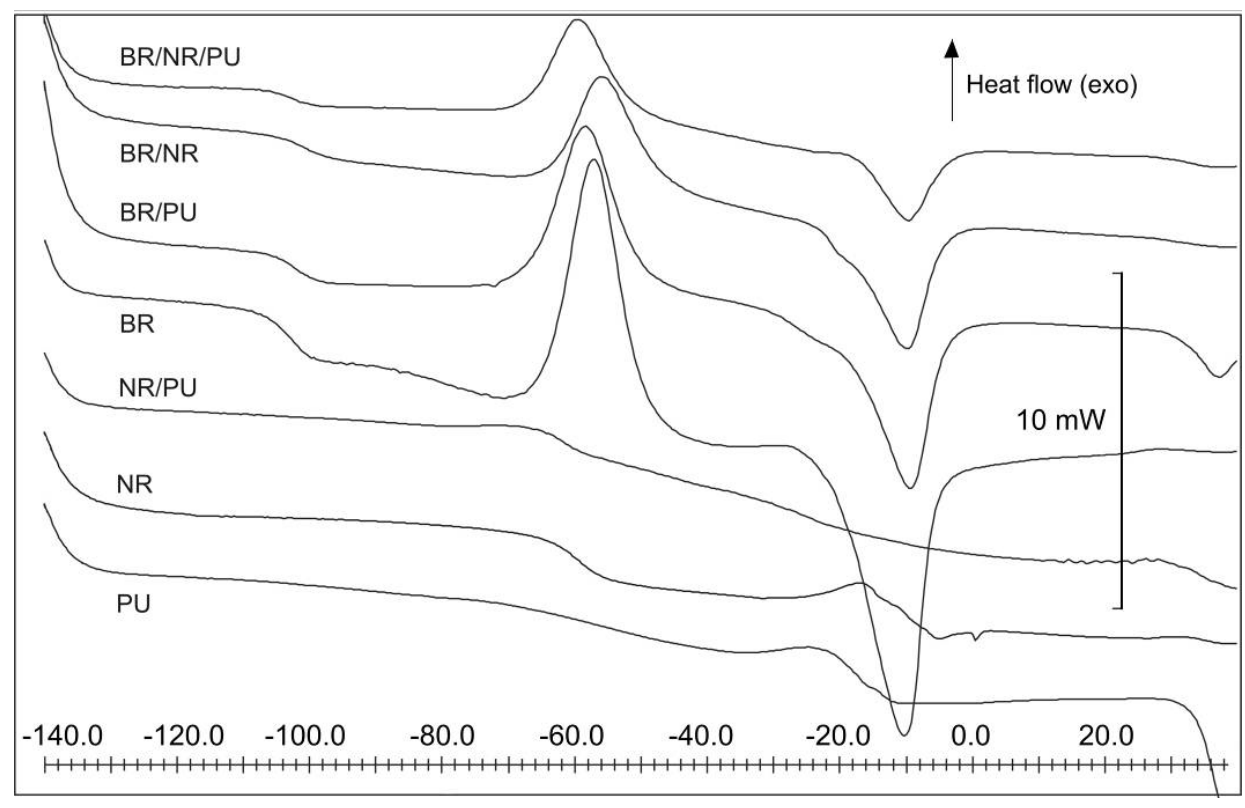

Fig. 6. The DSC thermograms of $B R, N R, P U, B R / N R, B R / P U, N R / P U$, and BR/NR/PU compounds.

Tab. 3. Results from DSC thermograms of different compounds - morphology study.

\begin{tabular}{lcccccccc}
\hline Blend & $\begin{array}{c}T_{g} \\
\left({ }^{\circ} \mathrm{C}\right)\end{array}$ & $\begin{array}{c}\Delta C_{p} \\
\left(\mathrm{Jg}^{-1} \mathrm{~K}^{-1}\right)\end{array}$ & $\begin{array}{c}T_{c} \\
\left({ }^{\circ} \mathrm{C}\right)\end{array}$ & $\begin{array}{c}\Delta H_{c} \\
\left(\mathrm{Jg}^{-1}\right)\end{array}$ & $\begin{array}{c}\Delta H_{c B R} \\
\left(\mathrm{Jg}^{-1}\right)\end{array}$ & $\begin{array}{c}T_{m} \\
\left({ }^{\circ} \mathrm{C}\right)\end{array}$ & $\begin{array}{c}\Delta H_{m} \\
\left(\mathrm{Jg}^{-1}\right)\end{array}$ & $\begin{array}{c}\Delta H_{m B R} \\
\left(\mathrm{Jg}^{-1}\right)\end{array}$ \\
\hline BR & -104 & 0.24 & -57 & 16.2 & 29.4 & -11 & 18.3 & 33.2 \\
NR & -60 & 0.36 & -16 & 1.6 & - & -5 & 1.3 & - \\
PU & -56 & 0.22 & - & - & - & - & - & - \\
& -17 & 0.40 & & & & & & \\
BR/NR & -101 & 0.23 & -56 & 9.9 & 27.6 & -10 & 0.3 & 28.8 \\
BR/PU & -102 & 0.23 & -58 & 14.2 & 30.2 & -10 & 13.9 & 29.4 \\
& -28 & 0.19 & & & & & & \\
NR/PU & -64 & 0.28 & - & - & - & - & - & - \\
& -21 & 0.36 & & & & & & \\
BR/NR/PU & -103 & 0.13 & -59 & 8.8 & 27.3 & -10 & 5.7 & 17.7 \\
& -25 & 0.01 & & & & & & \\
\hline
\end{tabular}

The curve of the BR compound showed a typical glass transition temperature $\left(T_{g}\right)$ at $-104{ }^{\circ} \mathrm{C}$. Since the used BR was a very high cis homopolymer, a large cold crystallization peak $\left(T_{c}\right)$ at $-57{ }^{\circ} \mathrm{C}$ and a melting peak $\left(T_{m}\right)$ at $-11{ }^{\circ} \mathrm{C}$ were also observed. For the NR compound a glass transition temperature at $-60{ }^{\circ} \mathrm{C}$ was determined. In the thermogram a smaller exothermic peak due to the cold crystallization followed by an endothermic peak of melting was observed between -30 
and $10{ }^{\circ} \mathrm{C}$. In contrast with the DSC results obtained for pure PU (Figure 5) two distinct glass transition temperatures $\left(T_{g}\right)$ at $-56{ }^{\circ} \mathrm{C}$ and $-17{ }^{\circ} \mathrm{C}$ were observed in the thermogram of the PU compound (Figure 6). The lower $T_{g}$ belonged to the PU soft segment rich phase, while the higher $T_{g}$ corresponded to the hard PU segments. An endothermic peak due to the melting of PU soft segments was observed at temperatures above $30{ }^{\circ} \mathrm{C}$ (see Figure 9, below). By comparing PU thermograms in Figures 5 and 6 it can be assumed that after blending PU with all the additives the degree of its crystallinity was lowered. It seems that the presence of additives restrained, to some extent, the alignment of soft segments into crystalline domains. Therefore, the determination of the two glass transition temperatures, below and above the $T_{g}$ determined for pure PU, was possible. The $T_{g}$ of PU soft segment rich phase (in Figure 6) was higher than that of polyol $\left(-62^{\circ} \mathrm{C}\right)$ indicating interactions between soft phase and hard PU segments. For polyester PUs hydrogen bonds between polyester polyol $\mathrm{C}=\mathrm{O}$ and urethane $\mathrm{N}-\mathrm{H}$ groups are characteristic.

Regrettably, it can be observed in Figure 6 that the $T_{g}$ of $N R$, the $T_{g}$ of PU soft segment rich phase, and the crystallization peak of BR occurred in a narrow temperature interval. Consequently, the $T_{g}$ of NR and the $T_{g}$ of PU soft segment rich phase in the NR/PU compound as well as in the compounds containing BR could not be evaluated. By observing the $T_{g}$ shifts, which indicate polymer-polymer interface occurrence, in BR/PU, NR/PU, and BR/NR/PU compounds the following can be observed:

For the BR/PU compound the $T_{g}$ of PU hard segments shifted from $-17^{\circ} \mathrm{C}$ (observed in PU thermogram) to $-28{ }^{\circ} \mathrm{C}$, whereas the BR $T_{g}$ did not shift considerably (from $104{ }^{\circ} \mathrm{C}$ to $\left.-102{ }^{\circ} \mathrm{C}\right)$ due to the high amount of BR in the rubber compound $(85.4 \%$ of $\mathrm{BR}$ and $14.6 \%$ of PU). Nonetheless, the $T_{g}$ shift of $-11{ }^{\circ} \mathrm{C}$ for PU hard segments might indicate a certain degree of PU miscibility with BR. The $T_{g}$ of PU soft segment rich phase in this compound could not be detected because of its overlapping with the BR crystallization peak, as already explained above.

In the NR/PU compound thermogram the PU soft segment rich phase $T_{g}$ occurred in the range of NR glass transition and the determination of distinct $T_{g}$ 's was not possible. As in the NR/PU compound thermogram the crystallization and melting peaks typical for the NR were not observed, the $T_{g}$ of PU hard segments for this compound was determined. Due to the absence of a NR cold crystallization peak it may be assumed that some interface between NR and PU domains occurred. The same conclusion might also be reached by observing the $T_{g}$ shift of PU hard segments (from $-17{ }^{\circ} \mathrm{C}$ in $\mathrm{PU}$ to $-21{ }^{\circ} \mathrm{C}$ in NR/PU), although this shift may be considered negligible.

To study the morphology of the BR/NR/PU compound its thermogram was compared to the BR/NR compound thermogram. For the BR/NR/PU compound $T_{g}$ of PU hard segments shifted from $-17^{\circ} \mathrm{C}$ to $-25{ }^{\circ} \mathrm{C}$ indicating a certain degree of PU miscibility with the BR/NR blend, even though the $T_{g}$ signal of PU hard segments was very weak due to a low PU concentration. Miscibility could be confirmed also by the observation of $\Delta H_{m B R}$ for the $\mathrm{BR}, \mathrm{BR} / \mathrm{PU}, \mathrm{BR} / \mathrm{NR}$ and $\mathrm{BR} / \mathrm{NR} / \mathrm{PU}$ compounds. If $\Delta H_{m B R}$ of the BR compound is compared to $\Delta H_{m B R}$ of the BR/NR compound to some extent lowered value for the BR/NR blend can be observed. When PU was added to the BR blend a similar decrease was obtained, although the amount of added PU was much lower than the amount of NR added to the BR blend. Furthermore, as PU was included in the BR/NR compound the value of $\Delta H_{m B R}$ considerably decreased (from 28.8 to $17.7 \mathrm{Jg}^{-1}$ ) which was a sign of enhanced interface formation in 
BR/NR/PU compound. The estimated $\Delta H_{C B R}$ value for the same compound only slightly decreased due to the overlapping of the NR $T_{g}$ and BR crystallization peaks.

By comparing thermograms of non-vulcanized one-component compounds with thermograms of multi-component compounds it was observed that the latter differed from thermograms of typical immiscible blends. In general, an immiscible blend has a thermogram which shows all characteristic thermal responses belonging to distinct components at temperatures typical for pure compounds. Therefore, it may be concluded that some mixing occurred between elastomers and PU at polymerpolymer interfaces of multi-component compounds.

\section{Vulcanization of compounds}

Despite the fact that the reactivity of the vulcanization system obtained by nonisothermal DSC and rheometer data cannot be compared, more useful information about the complex vulcanization reaction system can be obtained by using both techniques. When DSC and rheometer results are compared it has to be considered what each individual technique measures. Rheometers give information on the scorch delay and optimum cure time from the torque-time curve reflecting the degree of vulcanization. DSC measures reaction heat and peak temperature of the complex vulcanization process. Reaction heat from DSC does not have a simple correspondence to the generation of crosslinks observed from the cure meter - it involves the reaction heat due to crosslinking plus the reaction heat due to overcure reactions. Regrettably, it is practically impossible to isolate only the exothermic heat due to crosslinking in a DSC thermogram.

The continuous cure characteristics and the processability of the compounds were studied by using the Monsanto Rheometer (RPA 2000) at $160{ }^{\circ} \mathrm{C}$. In Figure 7 the cure curves of compounds are shown.

Tab. 4. Results from RPA analysis of $N R, B R, N R / B R$ compounds, and their compounds with PU.

\begin{tabular}{lccccc}
\hline Blend & $\begin{array}{c}T_{\min } \\
(\mathrm{dNm})\end{array}$ & $\begin{array}{c}T_{\max } \\
(\mathrm{dNm})\end{array}$ & $\begin{array}{c}T_{\max }-T_{\min } \\
(\mathrm{dNm})\end{array}$ & $\begin{array}{c}t_{02} \\
(\mathrm{~min})\end{array}$ & $\begin{array}{c}t_{90} \\
(\mathrm{~min})\end{array}$ \\
\hline BR & 2.16 & 10.44 & 8.28 & 5.79 & 12.22 \\
NR & 1.55 & 8.52 & 6.97 & 3.72 & 6.39 \\
BR/NR & 1.47 & 8.88 & 7.41 & 5.90 & 10.44 \\
BR/PU & 1.78 & 9.56 & 7.78 & 6.11 & 12.26 \\
NR/PU & 0.44 & 5.13 & 4.69 & 5.01 & 9.45 \\
BR/NR/PU & 1.34 & 8.34 & 7.00 & 6.08 & 10.72 \\
\hline
\end{tabular}

The minimum and maximum torque $\left(T_{\min }\right.$ and $\left.T_{\max }\right)$, delta torque $\left(T_{\max }-T_{\min }\right)$, the scorch time - the time for a $2 \%$ rise in torque from the minimal torque $\left(t_{02}\right)$, and the optimum cure time - the time for a $90 \%$ rise in torque from the minimum torque are collected in Table 4. In Figure 7 and in Table 4, it can be seen that the $T_{\min }$ and $T_{\max }$ decreased as the NR component was added to the BR component and further decreased when PU was added to the BR/NR rubber compound. Together with $T_{\min }$ 
and $T_{\max }$ the $T_{\max }-T_{\min }$ value decreased as well. The lowered $T_{\min }$ indicated a better processability of the composites including thermoplastic PU which melted at processing temperature, thereby allowing improvement in blend viscosity mold flow. Regarding the applicative properties of the BR/NR and the BR/NR/PU blend an insignificant decrease in $T_{\max }-T_{\min }$ value for the BR/NR/PU compound can be observed. This decrease might be attributed to the lower amount of elastomer capable of higher crosslinking degree.

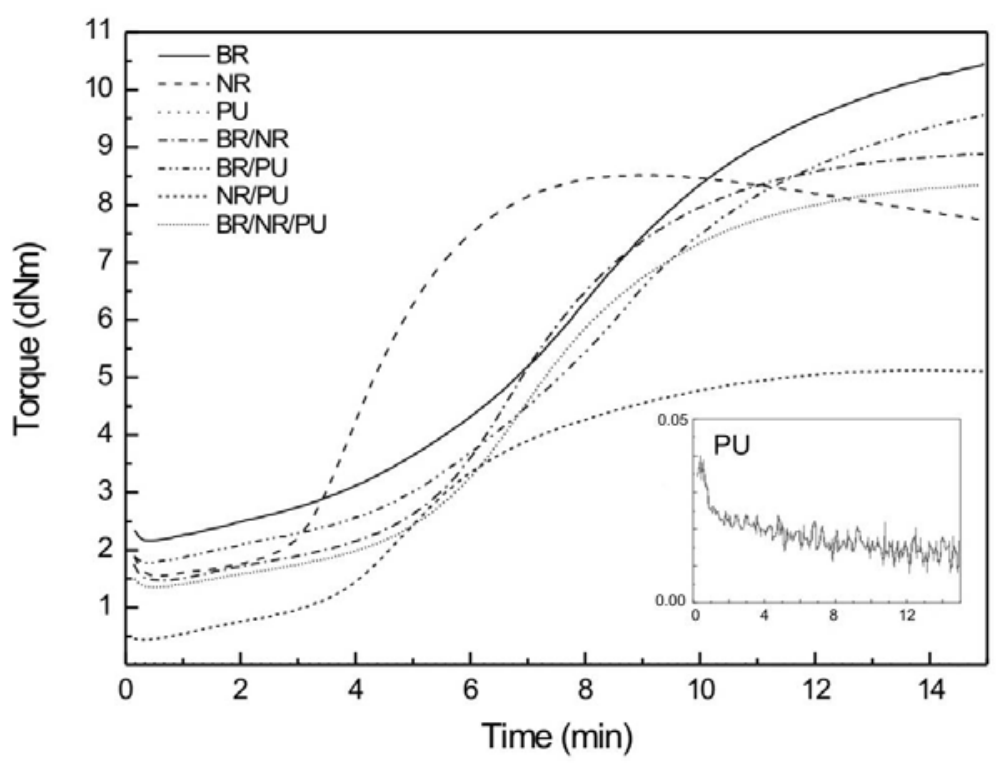

Fig. 7a. The cure curves (torque - time) of BR, NR, PU, BR/NR, BR/PU, NR/PU, and $\mathrm{BR} / \mathrm{NR} / \mathrm{PU}$ compounds.

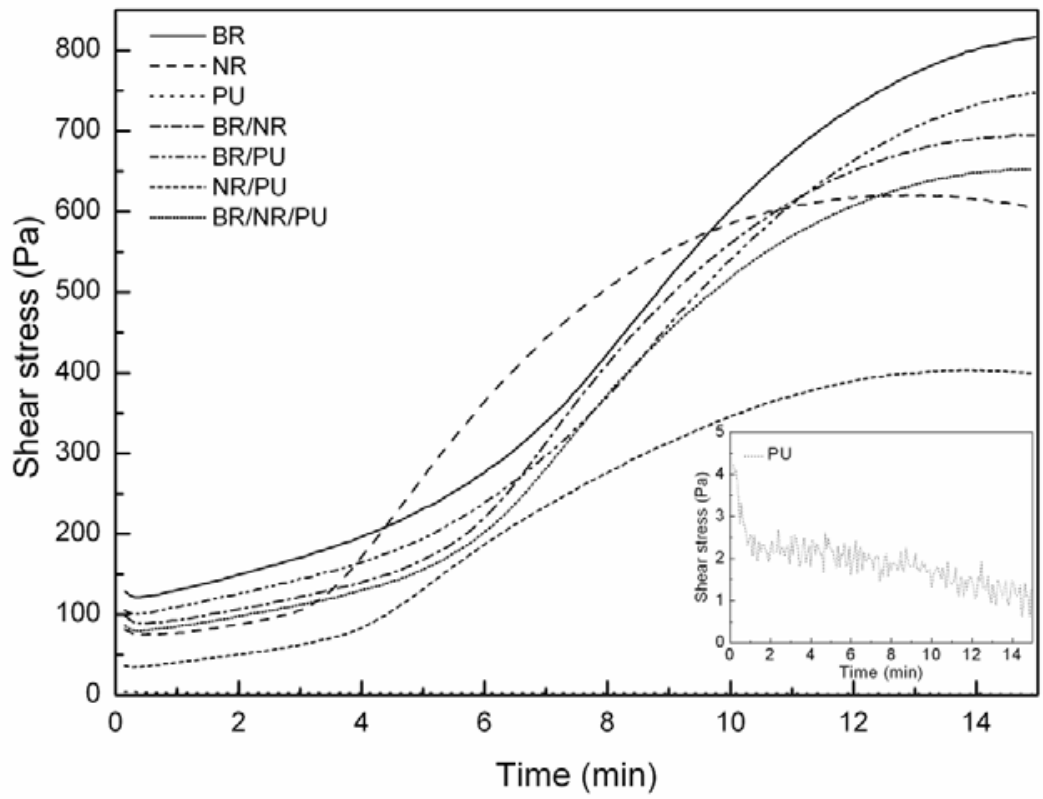

Fig. 7b. The cure curves (shear stress - time) of BR, NR, PU, BR/NR, BR/PU, NR/PU and BR/NR/PU compounds. 
Kim [17] studied the possibility of adding a thermoplastic elastomer to NR compound to improve NR scorch resistance. He observed that by blending styreneethylene/butylene-styrene with NR the scorch time increased by almost two times. By blending thermoplastic PU with BR, NR, and BR/NR blends, the scorch time $\left(t_{02}\right)$ increased in all the cases. This means the scorch resistance was increased by $P U$ incorporation into the compounds. In our work, the increase of $t_{02}$ for the NR/PU compound is the highest due to the highest PU/elastomer weight ratio. Regarding the optimum cure time, the BR/NR had a slightly lower $t_{90}$ than the BR/NR/PU compound, while the $t_{90}$ of the BR compound was significantly higher than both.

To compare reactivity of different rubber compounds and to confirm that the synthesized PU was able to crosslink with the elastomer components during the vulcanization process, a nonisothermal DSC analysis was carried out. The thermograms of the vulcanization are shown in Figure 8 where it can be seen that at chosen DSC conditions (heating rate $10^{\circ} \mathrm{C} / \mathrm{min}$ ) vulcanization peaks started and ended at different temperatures depending on the compound composition. It seems, that under such conditions PU and BR compounds started to decompose slowly at temperatures higher than $250{ }^{\circ} \mathrm{C}$, whereas the NR compound thermogram showed no heat flow increase in the investigated region of temperatures (Figure 8).

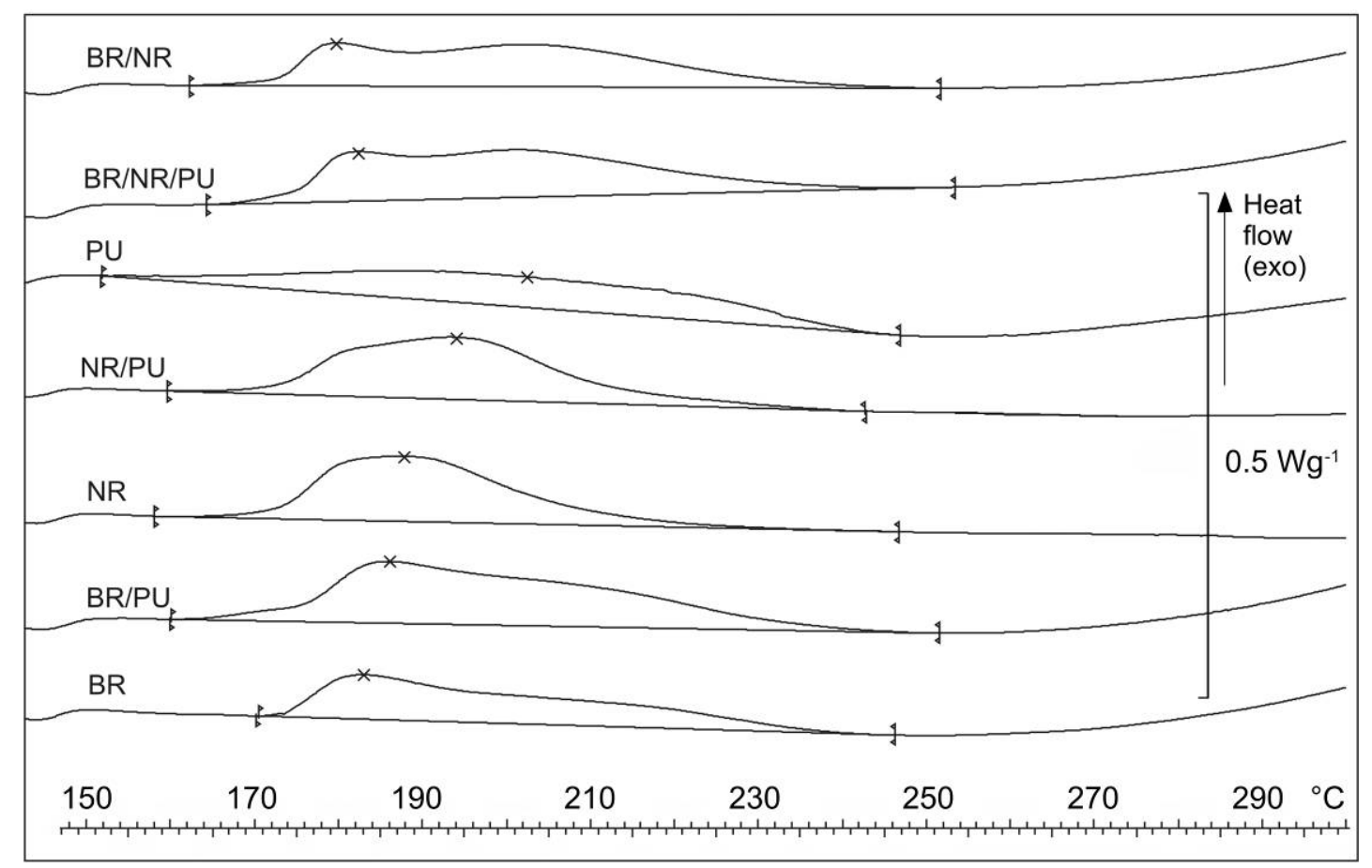

Fig. 8. The DSC thermograms of vulcanization of $B R, N R, P U, B R / N R, B R / P U$, NR/PU, and BR/NR/PU compounds.

As explained above, heats of vulcanization $\left(\Delta H_{v}\right)$ measured by the DSC technique include the reaction heat due to crosslinking plus the reaction heat due to overcure reactions. To omit wrong conclusions regarding the crosslinking heat of a singleor/and a multi-component compound the following discussion is based on the comparison of estimated $\Delta H_{v}$ values for different blends. In addition, theoretical values of $\Delta H_{v}$ for multi-component compounds were calculated from measured $\Delta H_{v}$ values of $B R, N R$, and $P U$ compounds by considering their weight ratios in a multi- 
component compound. The measured $\Delta H_{V}$ values are presented in Table 5 together with calculated $\Delta H_{v}$ for $\mathrm{BR} / \mathrm{PU}, \mathrm{NR} / \mathrm{PU}, \mathrm{BR} / \mathrm{NR}$, and BR/NR/PU compounds.

Tab. 5. DSC Results of NR, BR, and PU compounds, and compounds from their blends - vulcanization study.

\begin{tabular}{lcc}
\hline Blend & $\begin{array}{c}\text { measured } \Delta H_{v} \\
\left(\mathrm{~J} \mathrm{~g}^{-1}\right)\end{array}$ & $\begin{array}{c}\text { calculated } \Delta H_{v} \\
\left(\mathrm{~J} \mathrm{~g}^{-1}\right)\end{array}$ \\
\hline BR & 10.2 & - \\
$\mathrm{NR}$ & 10.6 & - \\
$\mathrm{PU}$ & 9.1 & - \\
$\mathrm{BR} / \mathrm{NR}$ & 11.4 & 10.3 \\
$\mathrm{BR} / \mathrm{PU}$ & 14.1 & 10.0 \\
$\mathrm{NR} / \mathrm{PU}$ & 11.3 & 10.2 \\
BR/NR/PU & 12.4 & 10.2 \\
\hline
\end{tabular}

The determined heats of vulcanization for BR/PU, NR/PU, BR/NR, and BR/NR/PU compounds were higher than the calculated ones. Moreover, the measured vulcanization heats of the BR/PU compound, the NR/PU compound, and the $B R / N R / P U$ compound were also higher than those of $B R$, NR, and BR/NR compounds, although the $\Delta \mathrm{H}_{\mathrm{v}}$ value of PU was the lowest among all the compounds. These observations revealed that some crosslinking between different components occurred during vulcanization in which double bonds reacted. The measured and calculated $\Delta H_{v}$ values for multi-component compounds could be compared even if an important part of $\Delta H_{v}$ was due to the overcure reactions. We believe, that if crosslinking between different components occurs, the measured and calculated $\Delta H_{v}$ values, which include cure and overcure heat, should be different.

If BR/PU and NR/PU $\Delta H_{v}$ values are compared, a considerably higher $\Delta H_{v}$ value for the BR/PU compound can be observed, despite the fact that the weight ratio between elastomer and PU was not the same. The higher heat of vulcanization can be ascribed to the higher extent of reaction between BR and PU, which depended on the amount of the interface formed between the two components. The DSC analysis discussed above showed that the $T_{g}$ shift of PU hard segments for BR/PU compound was larger than that for NR/PU compound, what indicated a higher degree of PU miscibility with BR than with NR. Presumably, between PU and BR much interface could be formed during blending since the BR rubber had a more uniform chain structure of lower average molecular weight and narrower molecular weight distribution.

Therefore, on the basis of DSC results it was concluded, that the synthesized unsaturated PU was able to crosslink with the elastomer components during the vulcanization process, which could not be observed from RPA cure curves. The amount of crosslinks formed between the components depended on the amount of the interface between them which is in general affected by mixing efficiency and polymer-polymer miscibility. 


\section{Vulcanized blends characterization}

To check the thermal response of vulcanized compounds in the temperature region of PU melting, DSC thermograms of vulcanized and non-vulcanized compounds of the same composition were compared. The thermograms of vulcanized and nonvulcanized BR/NR/PU compound in the temperature interval of interest are shown in Figure 9. By examining DSC thermograms of vulcanized compounds it was observed that they did not have the endothermic peak due to the PU melting which occurred in thermograms of the non-vulcanized compounds. This indicated that the PU was crosslinked in the vulcanized compounds.

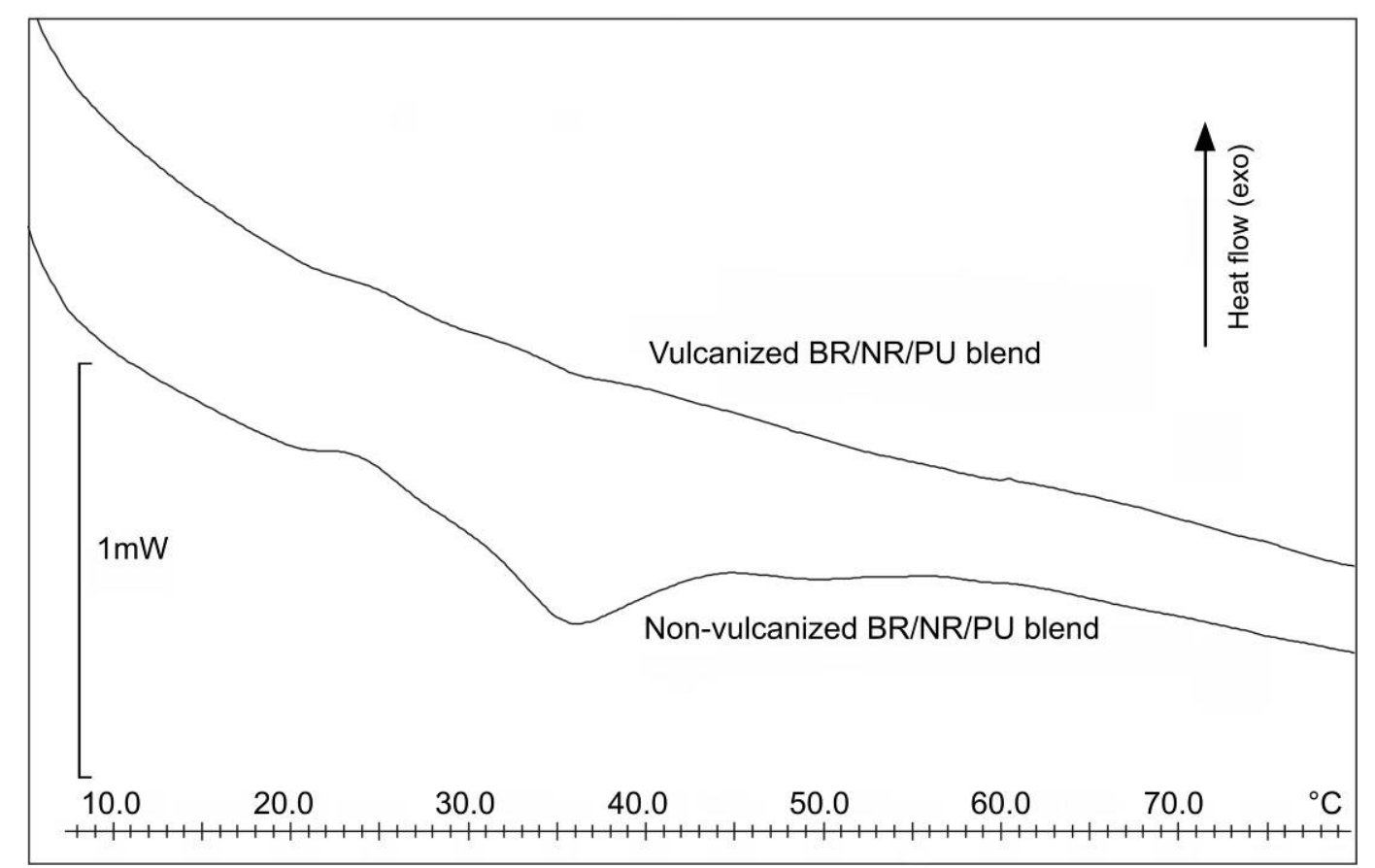

Fig. 9. The DSC thermograms of vulcanized and unvulcanized BR/NR/PU compound in the region of soft segment melting temperature

Tab. 6. Results of after cure dynamic properties of different compounds using a RPA (strain sweep test, $100^{\circ} \mathrm{C}, 6.28 \mathrm{rad} / \mathrm{s}$ ).

\begin{tabular}{lcc}
\hline Blend & $\begin{array}{c}G^{*} \\
(\mathrm{kPa})\end{array}$ & $\begin{array}{c}\tan \delta \text { at } 13.95 \% \text { deformation } \\
(/)\end{array}$ \\
\hline $\mathrm{BR}$ & 785.5 & 0.106 \\
$\mathrm{NR}$ & 572.7 & 0.064 \\
$\mathrm{PU}$ & 3.6 & 1.276 \\
$\mathrm{BR} / \mathrm{NR}$ & 669.3 & 0.078 \\
$\mathrm{BR} / \mathrm{PU}$ & 713.0 & 0.112 \\
$\mathrm{NR} / \mathrm{PU}$ & 375.8 & 0.195 \\
$\mathrm{BR} / \mathrm{NR} / \mathrm{PU}$ & 628.8 & 0.085 \\
\hline
\end{tabular}


In Table 6 the dynamic properties of different compounds after cure measured by RPA, applying a strain sweep test at $100{ }^{\circ} \mathrm{C}$ and frequency of $6.28 \mathrm{rad} / \mathrm{s}$, are collected. It can be seen that the complex modulus $\left(G^{*}\right)$ of elastomer compounds (at $13.95 \%$ deformation) was lowered when the PU was added. The $G^{*}$ of the BR compound decreased as the NR component was added and further decreased when thermoplastic PU was added to the BR/NR rubber compound. The NR/PU compound had the lowest $G^{*}$ among all the compounds with PU because the highest amount of $\mathrm{PU}$ was used for this compound. For all investigated rubber compounds, except for $\mathrm{PU}$, the storage modulus prevailed over the loss modulus. Tan $\delta$ of the BR/NR compound increased only slightly as PU of high tan $\delta$ was added to the compound.

In Table 7 physical properties of vulcanized specimens (measured using a Zwick UTM Model 1465 according to ASTM D412-80 and using a Karl Frank 38210 tester with Shore A durometer) are shown. It was observed that vulcanized BR, NR, and NR/BR specimens, if compared to the vulcanized BR/PU, NR/PU, and BR/NR/PU specimens, had higher Shore A hardness, higher modulus, and higher tensile strength, while the elongation at break remained in the same order of magnitude. The Shore A hardness, modulus, and tensile strength of the BR/NR/PU2 specimen, which had a lower content of PU (5\%, the specimen BR/NR/PU had $10 \%$ of PU) did not differ significantly from those of the BR/NR specimen. Hence, the elongation at break was observed to be slightly higher.

Similar results were obtained by Desai et al. who studied polyurethane and nitrile rubber blends [18]. They correlated this phenomenon to the existence of satisfactory rubber matrix adhesion in the composition of interest, which prevented interfacial decohesion. Their observations were confirmed by a morphology study where SEM analysis was applied.

Tab. 7. Physical properties of vulcanized specimens.

\begin{tabular}{lccccccc}
\hline Blend & $\begin{array}{c}\text { Hardness } \\
(\text { Shore A) }\end{array}$ & $\begin{array}{c}M_{50} \\
(\mathrm{MPa})\end{array}$ & $\begin{array}{c}M_{100} \\
(\mathrm{MPa})\end{array}$ & $\begin{array}{c}M_{200} \\
(\mathrm{MPa})\end{array}$ & $\begin{array}{c}M_{300} \\
(\mathrm{MPa})\end{array}$ & $\begin{array}{c}\text { Tensile } \\
\text { strength } \\
(\mathrm{MPa})\end{array}$ & $\begin{array}{c}\text { Elongation } \\
\text { at break } \\
(\%)\end{array}$ \\
\hline BR & 45.9 & 0.75 & 1.11 & 2.14 & 3.79 & 13.7 & 720 \\
NR & 41.8 & 0.59 & 0.98 & 2.33 & 4.75 & 18.9 & 646 \\
$\mathrm{PU}$ & - & - & - & - & - & - & - \\
BR/NR & 42.2 & 0.65 & 0.98 & 1.97 & 3.72 & 15.4 & 723 \\
BR/PU & 45.0 & 0.70 & 1.04 & 1.95 & 3.40 & 10.7 & 722 \\
NR/PU & 39.4 & 0.55 & 0.93 & 2.23 & 4.19 & 13.7 & 641 \\
BR/NR/PU & 40.8 & 0.62 & 0.94 & 1.91 & 3.60 & 13.5 & 707 \\
BR/NR/PU2 & 43.2 & 0.67 & 1.01 & 2.01 & 3.72 & 15.1 & 762 \\
\hline
\end{tabular}

To verify that the addition of PU to the blends did not worsen their thermal stability TGA measurements of vulcanized compounds were carried out in air. Figure 10 shows degradation profiles of different vulcanized samples. 


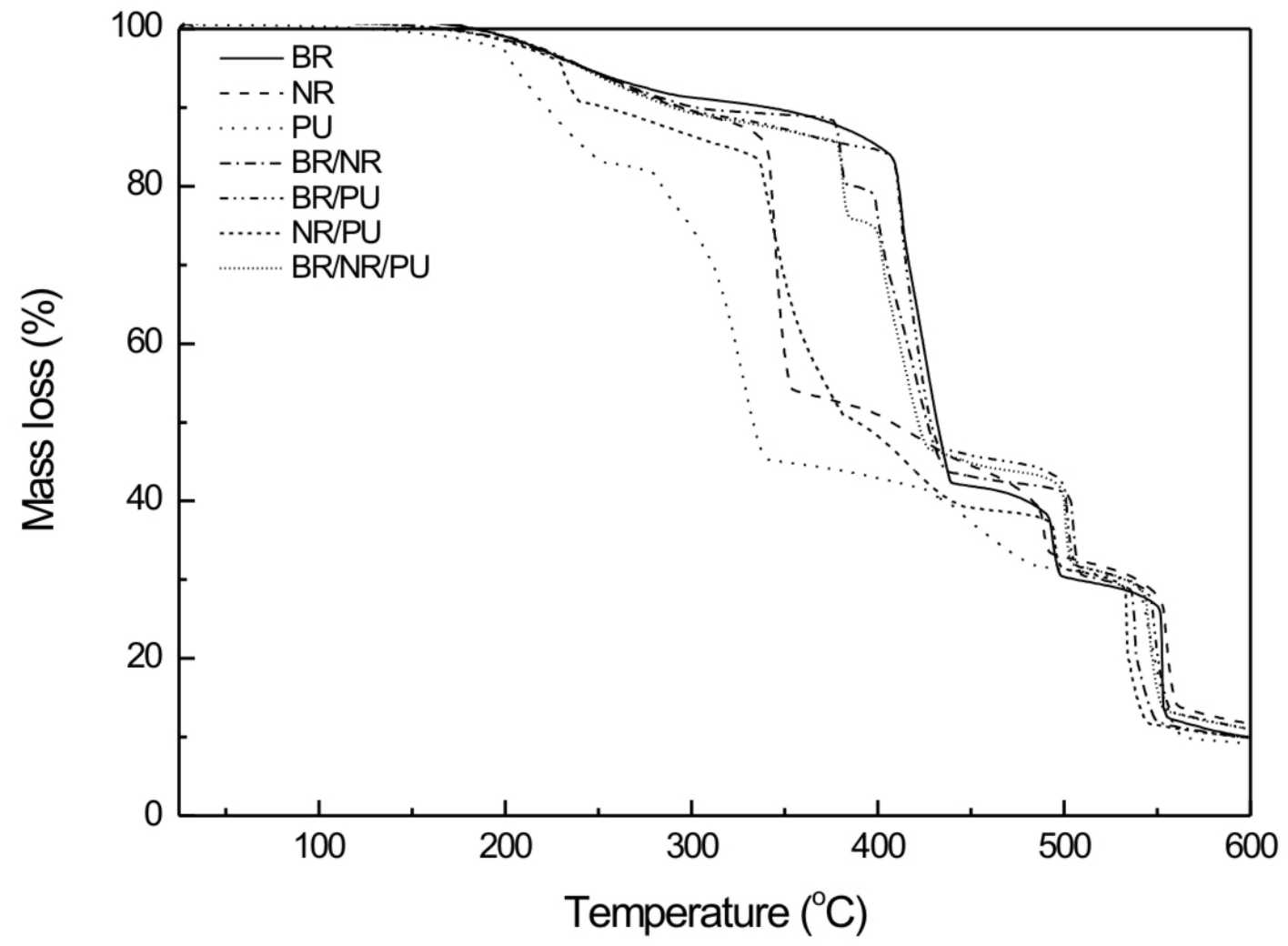

Fig. 10. The TGA thermograms of $B R, N R, P U, B R / N R, B R / P U, N R / P U$, and BR/NR/PU vulcanized compounds.

Curve shapes indicated that the thermal degradation mechanisms of the studied samples were very complex and occurred in several steps. Heat-aging weight loss for vulcanized BR, NR, and PU compounds showed a distinct order of thermal stability as follows: BR $>$ NR $>$ PU. The thermal stability of BR/NR, BR/PU, NR/PU, and BR/NR/PU compounds lay between pure blends and was more similar to the stability of the elastomer blend (BR or NR) which was in the majority. If the $\mathrm{NR/BR/PU}$ compound is compared to the NR/BR compound, to some extent lowered thermal stability of the NR/BR/PU compound can be observed due to the PU oxidative degradation between 300 and $400{ }^{\circ} \mathrm{C}$. At temperatures between 200 and $325^{\circ} \mathrm{C}$ the weaker urethane, aliphatic, aromatic, and esteric groups in the PU backbone is dissociated. Nevertheless, it can be concluded, on the basis of TGA analysis, that the thermal stability of compounds containing the used amount of PU was not significantly worse than those of compounds without PU.

To study the morphology of the vulcanized compounds and to verify if the introduction of PU in the BR/NR compound had somehow improved its homogeneity several SEM photographs were taken. A representative SEM image of the BR/NR compound is presented in Figure 11. The figure shows how the bright regions are dispersed in the continuous dark phase. A similar SEM image of a BR/NR compound was obtained by Saad et al. [11]. The authors, by interpreting the SEM image, stated that the BR/NR compound was compatible as dark and bright regions representing both polymers were distributed homogeneously and none of the regions had phase separation. From our SEM results it cannot be confirmed that the bright and dark regions represented different elastomers as the bright and dark regions were observed also in images of pure BR and pure NR compounds. 


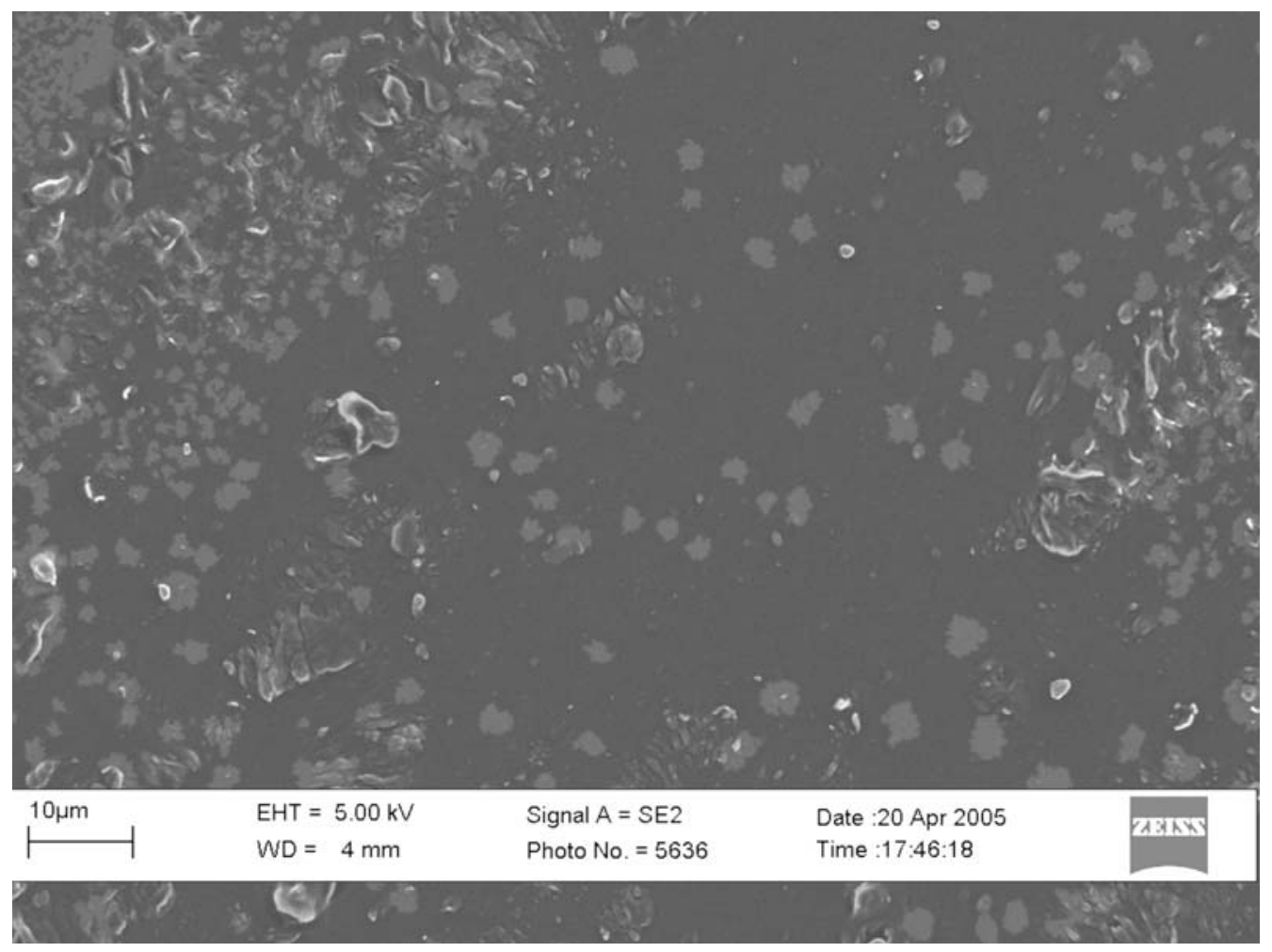

Fig. 11. The SEM image of vulcanized BR/NR compound.

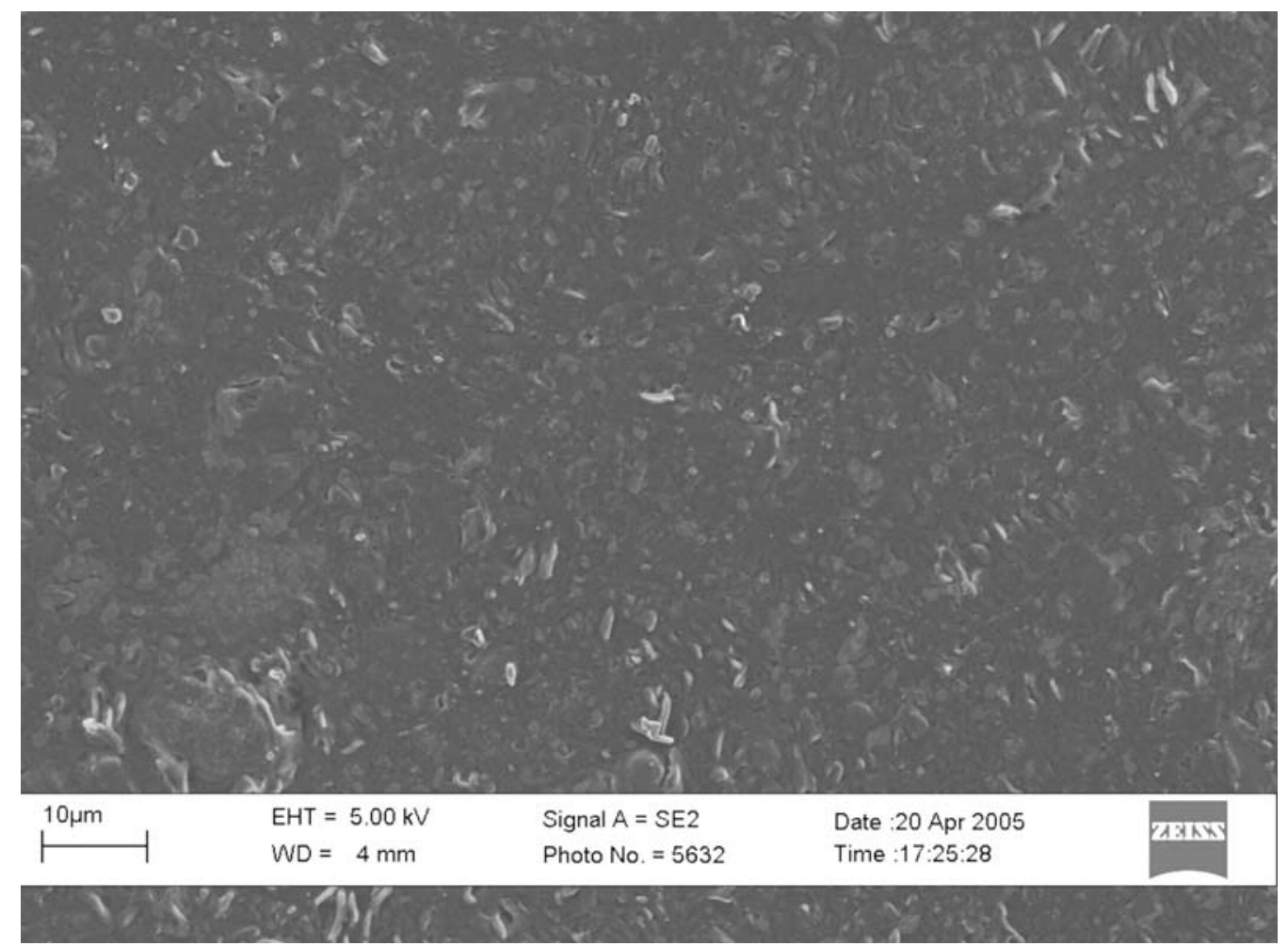

Fig. 12. The SEM image of vulcanized BR/NR/PU compound.

Nevertheless, it is believed, that bright regions represented the elastomer of higher molecular weight, while the elastomer of lower molecular weight was observed as a 
continuous dark region in the SEM image. In Figure 11 the dispersed bright domains were of different sizes, the larger ones had a diameter of cca. $3 \mu \mathrm{m}$, and were nonuniformly distributed over the matrix.

In Figure 12 a representative SEM image of the BR/NR/PU compound is shown. By comparing Figures 11 and 12 it can be observed that in the BR/NR/PU compound the bright domains representing polymers of higher molecular weight were more homogeneously distributed through the dark matrix and that they were smaller than those observed in the NR/BR compound. As the amount of PU in the BR/NR/PU compound with all the additives was less than $10 \%$, distinct PU domains or regions were not observed in the SEM image.

Regarding the SEM analysis results it may be concluded that the addition of PU to the BR/NR compound had improved its homogeneity to some extent since polymer domains of different molecular weight were more homogeneously distributed throughout the compound.

\section{Conclusions}

To improve the BR/NR blend processability and to obtain a more homogeneous blend a thermoplastic unsaturated polyurethane (PU) was added to the blend. It was observed that the synthesized PU was able to crosslink with the rubber components during the vulcanization process. The lowered $T_{\min }$ indicated a better processability of the composites including thermoplastic PU which melted at processing temperature, thereby allowing improvement in blend viscosity mold flow. However, the comparison of mechanical properties of the prepared elastomer compounds, with and without PU, showed that they exhibited comparable hardness, tensile strength, modulus, and elongation at break, including the thermal stability which was not worsened significantly. To develop a BR/NR/PU compound with enhanced mechanical properties an unsaturated PU of different chemical structure should be used. A branched PU prepared from lower molecular weight polyol or even better a PU with free isocyanate groups would certainly improve the mechanical properties of the rubber compound.

\section{Experimental part}

\section{Materials}

2-Hydroxyethyl methacrylate (HEMA)(99+\%, Aldrich, UK), toluene-2,4-diisocyanate (TDI) (98\%, Fluka AG, Swietzerland), 1,500 molecular weight poly (hexamethylene adipate) (supplied by Helios, Slovenia), dibutyltin dilaurate (DBTDL) (95\%, Merck, Germany), polybutadiene rubber (BR), natural rubber (NR), commercial additives, such as carbon black (N660), sulphur, zinc oxide, stearic acid, dibenzothyazil disulfide, and $\mathrm{N}$-cyclohexylthiophthalimide were used. For the NR and BR average molecular weights were determined by gel permeation chromatography (GPC) using polystyrene standards. For non-masticated NR the weight average molecular weight was $1.25 \cdot 10^{6}$ and the polydispersity index was 5.1 . After mastication the NR weight average molecular weight was reduced to $8.2 \cdot 10^{5}$ and the polydispersity index was 3.7. The weight average molecular weight of non-masticated BR was $6.0 \cdot 10^{5}$ and the corresponding polydispersity index was 3.1. After mastication the BR average molecular weight did not change considerably. 


\section{Synthesis of $P U$}

The synthesis was carried out in a 4 neck glass reactor equipped with a stirrer, a reflux condenser, thermocouples, IR probe, and nitrogen gas inlet system. Firstly, polyol was poured into the reactor under a nitrogen atmosphere and heated up to $80^{\circ} \mathrm{C}$. In a separate vessel diisocyanate and DBTDL were stirred for 15 minutes under nitrogen atmosphere at room temperature. In the first step diisocyanate and DBTDL (0.1 wt. \% on PU weight) were added to the polyol. In this step 2 mols of diisocyanate were allowed to react with $1 \mathrm{~mol}$ of polyol. In the second step, after 190 minutes of the reaction of diisocyanate with polyol, 2 mols of HEMA were slowly poured into the reactor. In this step HEMA was reacted with the residual $\mathrm{N}=\mathrm{C}=\mathrm{O}$ groups at $80{ }^{\circ} \mathrm{C}$ for 120 minutes, capping both molecular ends with vinyl groups. During both steps the changes of absorbance peaks belonging to characteristic functional groups were monitored by the in-line FTIR-ATR spectroscopy using the Mettler Toledo ReactIR-4000 instrument coupled with a DiComp diamond probe. IR spectra were collected every 30 seconds in the wave number range between 4000 and $650 \mathrm{~cm}^{-1}$ at resolution $8 \mathrm{~cm}^{-1}$. The composition of PU is shown in Table 8.

Tab. 8. Composition of polyurethane.

\begin{tabular}{ll}
\hline \multicolumn{1}{c}{ Material } & mol \\
\hline Poly (hexamethylene adipate) & 1.0 \\
TDI & 2.0 \\
HEMA & 2.0 \\
\hline
\end{tabular}

\section{Methods for PU Characterization}

To confirm the desired PU chemical structure ${ }^{1} \mathrm{H},{ }^{13} \mathrm{C}$ NMR analysis was performed. The NMR spectra of PU were obtained by the Bruker DPX $300 \mathrm{MHz}$ instrument. $\mathrm{CDCl}_{3}$ was used as a solvent. The ${ }^{1} \mathrm{H}$ and ${ }^{13} \mathrm{C}$ signals were referred to tetramethylsilane (TMS) as the internal standard. A $2.0 \mathrm{sec}$ pulse delay time was used with the gated decoupling of protons for ${ }^{13} \mathrm{C}$ quantitative measurements.

Differential scanning calorimetry (DSC) was performed in order to characterize thermal response properties of the PU. The measurements were performed on a Mettler Toledo DSC $821^{\mathrm{e}}$ instrument with intra-cooler, using STAR software. In and $\mathrm{Zn}$ standards were used for the temperature calibration and for the determination of the instrument time constant. Measurements in the temperature range from - 120 to $300{ }^{\circ} \mathrm{C}$ at heating rates of 10 and $20^{\circ} \mathrm{C} \mathrm{min}{ }^{-1}$ were performed. Standard $40 \mu \mathrm{l}$ alumina pans were used.

X-ray diffraction was carried out to determine the PU degree of crystallinity. A Siemens D-5000 diffractometer (CuKa radiation, range from 2 to $60^{\circ} 2 \theta$, step $0.04^{\circ}$ $2 \theta$, integration time $1 \mathrm{~s}$, gap V20 and 0.6 ) was used to analyze partly crystalline polyol and PU sample.

The number average molecular weight $\left(M_{n}\right)$ and the weight average molecular weight $\left(M_{w}\right)$ of PU were determined by gel permeation chromatography (GPC) using polystyrene standards. The samples were dissolved in (1 \% w/v solutions) tetrahydrofuran, which was applied also as carrier solvent at a rate of $1 \mathrm{ml} \mathrm{min}^{-1}$. The PLgel mixed-bed $5 \mu \mathrm{m}(300 \times 7.5 \mathrm{~mm})$ column and Perkin Elmer series 200 pump in combination with Waters Associated differential refractometer were used. 


\section{Preparation of $N R, B R$, and $P U$ compounds}

Blending of the components was carried out on a Brabender plasticorder PLV-151 mixer at rotor speed of $60 \mathrm{rpm}$ at set temperature of $60{ }^{\circ} \mathrm{C}$. BR, NR, and PU blends with the additives were prepared first. Elastomers were preblended for 30 seconds and then carbon black and all the additives were mixed with the preblend for additional 10 or 7 minutes for NR and BR blends, respectively. PU blend was prepared at $40{ }^{\circ} \mathrm{C}$ by adding $\mathrm{PU}$ and additives simultaneously in sequential additions.

$\mathrm{BR} / \mathrm{NR}, \mathrm{BR} / \mathrm{PU}, \mathrm{NR} / \mathrm{PU}$, and BR/NR/PU compounds were obtained by blending BR, $\mathrm{NR}$, and PU blends (with all the additives included) using a two roll mixing mill with 1 $\mathrm{mm}$ gap. For each blending 30 passes through the mill were carried out. The compounding formulations of blends are given in Table 9.

Blends morphology was studied by a DSC method, using a scanning rate of $20^{\circ} \mathrm{C} / \mathrm{min}$ from -140 to $40^{\circ} \mathrm{C}$.

Tab. 9. Compounding formulations for different blends.

\begin{tabular}{lccc}
\hline Blend & BR wt. \% & NR wt. \% & PU wt. \% \\
\hline BR & 100 & 0 & 0 \\
NR & 0 & 100 & 0 \\
PU & 0 & 0 & 100 \\
BR/NR & 65.0 & 35.0 & 0 \\
BR/PU & 85.4 & 0 & 14.6 \\
NR/PU & 0 & 75.9 & 24.1 \\
BR/NR/PU & 58.5 & 31.5 & 10.0 \\
BR/NR/PU2 & 61.8 & 33.2 & 5.0 \\
\hline Additives in all blends listed above: carbon black (40 phr), ZnO \\
(4 phr), stearic acid (2 phr), sulfur (2.1 phr), benzothiazyl \\
disulfide (1.2 phr), and N-cyclohexylthiophthalimide (0.1)
\end{tabular}

\section{Vulcanization}

The continuous cure characteristics and the processability of the blends were studied by a Monsanto Rheometer (RPA 2000) at $160^{\circ} \mathrm{C}$.

Differential scanning calorimetry (DSC) was performed in order to characterize thermal response properties of the blends during vulcanization. The measurements were performed on the Mettler Toledo DSC $821^{\mathrm{e}}$ instrument described above. The measurements at non-isothermal conditions were performed in the temperature range from 20 to $300{ }^{\circ} \mathrm{C}$ in a nitrogen atmosphere at heating rates of $10^{\circ} \mathrm{C} \mathrm{min}{ }^{-1}$. Standard $40 \mu$ alumina pans were used.

Test specimens for physical properties testing were vulcanized at $160{ }^{\circ} \mathrm{C}$ in an electrically heated press for 15 minutes. 


\section{Methods for vulcanized compounds characterization}

The vulcanized compounds were tested on a Monsanto Rheometer (RPA 2000) at $100{ }^{\circ} \mathrm{C}$. Strain sweep tests at frequency $6.28 \mathrm{rad} / \mathrm{s}$ (in the range between 0.98 and $19.95 \%$ ) were performed.

Tensile strength, modulus, and elongation at break for vulcanized specimens were measured using a Zwick UTM Model 1465 according to ASTM D412-80. Calculated averages of five measurements were taken as results. Shore hardness was measured on a Karl Frank 38210 tester with Shore A durometer at several points on the surface of the specimen. An average of five measurements was used as a result.

The phase morphologies of compounds were studied by scanning electron microscopy (SEM) analysis using a JEOL JSM-T220 scanning electron microscope. The samples were imaged at $5 \mathrm{kV}$ accelerating voltage. Samples were coated with a thin layer of carbon to reduce any charge build-up on the fracture surface.

Thermogravimetric analysis of vulcanized compounds were performed on a Mettler Toledo TGA/SDTA $851^{\mathrm{e}}$ instrument using maximal resolution method in a temperature range from 25 up to $600{ }^{\circ} \mathrm{C}$. The parameters in maximal resolution method were set as follows: maximal heating rate $10 \mathrm{~K} \mathrm{~min}^{-1}$, minimal heating rate 1 $\mathrm{K} \mathrm{min}^{-1}$, high threshold $3 \mu \mathrm{Ms}^{-1}$, low threshold $1 \mu \mathrm{gs}^{-1}$, and factor 2 . That means when the weight loss exceeds $3 \mu^{-1}$, the heating rate was automatically lowered to $5 \mathrm{~K}$ $\mathrm{min}^{-1}$ (by factor 2). The initial mass of the sample was approximately $10 \mathrm{mg}$. Platinum crucibles (diameter $8 \mathrm{~mm}$ ) and dynamic air atmosphere with a flow rate of $100 \mathrm{ml}$ $\min ^{-1}$ were used.

\section{Acknowledgements}

The financial support of this work by the Slovenian Ministry of Higher Education, Science and Technology (Grant L2-6686) is gratefully acknowledged.

\section{References}

[1] Mark, J.E.; Erman, B.; Eirich, F.R.; Science and Technology of Rubber, Academic Press, San Diego 1994.

[2] Utracki, L.A.; Polymer Alloys and Blends, Hanser Publishers, Munich 1989.

[3] Coran, A.Y.; Patel, R.; Rubber Chem. Technol. 1980, 53 (1), 141.

[4] Bartenev, G.M.; Kongarov, G.S.; Rubber Chem. Technol. 1963, 36, 668.

[5] Walters, M.H.; Keyte, D.N.; Rubber Chem. Technol. 1965, 38, 62.

[6] Hess, W.M.; Scott, C.E.; Callan, J.E.; Rubber Chem. Technol. 1967, 40, 371.

[7] Hourston, D.J.; Song, M.; J. Appl. Polym. Sci. 2000, 76, 1791.

[8] Bualek, S.; Ikeda, Y.; Kohjiya, S.; Phaovibul, O.; Phinyocheep, P.; Suchiva, K.; Utani, K.; Yamashita, S.; J. Appl. Polym. Sci. 1993, 48, 807.

[9] Bauer, R.F.; Duddley, E.A.; Rubber Chem. Technol. 1977, 50, 35.

[10] Corish, P.J.; Rubber Chem. Technol. 1967, 40, 324.

[11] Saad, A.L.G.; El-Sabbagh, S.; J. Appl. Polym. Sci. 2001, 79, 60.

[12] Hasegawa, H.; Sakurai, S.; Takenaka, M.; Hashimoto, T.; Han, C.C.; Macromolecules 1991, 24 (8), 1813.

[13] Leblanc, J.L.; Kaut. Gummi. Kunstst. 1983, 36(6), 457.

[14] Ding, R.; Leonov, A.I.; J. Appl. Polym. Sci. 1996, 61, 455.

[15] Chough, S.H.; Chang, D.H.; J. Appl. Polym. Sci. 1996, 61, 449.

[16] Huson, M.G.; McGill, W.J.; Swart, P.J.; J. Polym. Sci. Polymer Letters Edition 1984, 22, 143. 
[17] Kim, J.K.; J. Appl. Polym. Sci. 1996, 61, 431.

[18] Desai, S.; Thakore, I.M.; Brennan, A.; Devi, S.; J. Macromol. Sci. Pure 2001, 38 (7), 711. 